Karlin Olbertz

\title{
OPERAÇÃO URBANA CONSORCIADA
}

\author{
Dissertação de Mestrado
}

Orientadora Professora Titular Odete Medauar

Faculdade de Direito da Universidade de São Paulo São Paulo 


\section{RESUMO}

A operação urbana consorciada é um instrumento de política urbana introduzido no ordenamento jurídico brasileiro pelo Estatuto da Cidade. Caracteriza-se pela disposição à intervenção urbanística e à regulação do mercado imobiliário e resulta na execução de um plano urbanístico flexível, em que há concessão de benefícios e recebimento de contrapartidas, mediante concertação público-privada, e participação, em todo o processo, da sociedade civil. Sua natureza jurídica é a de procedimento e o seu conteúdo confere-lhe o caráter de empreendimento urbano. Operações estrangeiras e outros modelos de operações no Brasil ofereceram inspiração à criação do instrumento. Há vícios que podem acometer a operação urbana consorciada, especialmente desvios de finalidade e valorização excessiva e não combatida das localizações. Mas há medidas orientadas a evitar a ocorrência desses vícios, tais como a adequada definição da área da operação, a realização de pequenas intervenções e de obras de interesse social, e o incentivo à gestão democrática e ao controle pela sociedade civil.

Palavras-chave: operações urbanas, Estatuto da Cidade, operação urbana consorciada. 


\begin{abstract}
Joint urban operation is an urban policy instrument introduced in the Brazilian legal system by the "City Act". It is defined by urban intervention and land property market regulation and results in the execution of a flexible urban plan, in which there are benefits provided and returned, through public-private partnerships, and the participation of all interested citizens throughout the process. Its legal nature is that of a procedure, characterized as an urban enterprise due to its content. Foreign operations and other types of Brazilian operations have inspired the creation of this instrument. There are flaws which may hinder joint urban operations, especially their misuse of purpose and the uncurbed overvalue of the locations. But there are measures to impede the occurrence of these flaws, such as a proper delimitation of the operation area, small interventions and social interest works, and the encouragement of democratic management and control by the civil society.
\end{abstract}

Keywords: Urban operations, City Act, joint urban operations. 


\section{INTRODUÇÃO}

O direito urbanístico é disciplina de formação recente, que demanda estudo e desenvolvimento no Brasil, sobretudo porque determinante do espaço habitável e, portanto, gerador de implicações absolutamente relevantes e próximas à vida de cada cidadão.

$\mathrm{O}$ objeto do presente trabalho insere-se no tema global do direito urbanístico. Pretende-se examinar a operação urbana consorciada, um instrumento de intervenção urbanística adotado no ordenamento jurídico nacional pelo Estatuto da Cidade (art. $4^{\circ}$, VI, "p", e art. 32).

A relevância do assunto decorre do fato de a operação urbana consorciada configurar-se como alternativa potencialmente vantajosa ao urbanismo, diante da redução quantitativa das funções do Estado. Isso porque, devido ao seu caráter concertado, a operação urbana consorciada é capaz de representar uma das respostas sobre como manter e fortalecer o Estado e a função pública do urbanismo. ${ }^{1}$

Ademais, a operação urbana consorciada pode configurar-se uma necessidade diante da realidade contemporânea, em que a capacidade de investimentos, gestão e controle pelo Estado também é reduzida. ${ }^{2}$

Nesse contexto, a participação da sociedade civil na formulação e na implementação do instrumento pode servir de contraponto à ampla submissão do espaço habitável ao mercado.

Inclusive, o mercado vem agindo livremente nesse espaço em face do déficit de controle e de planejamento públicos (ou, em última análise, do déficit de regulação pública da organização espacial). Como concluiu Odete MEDAUAR, "parece que os governantes brasileiros em geral sentem ojeriza por planejamento e por planos; por vezes, estes são

\footnotetext{
1 "Nas reflexões sobre a evolução das funções do Estado, tem-se discutido acerca da determinação do que é público, do que pertence à esfera pública, e que conduz à consideração do 'quanto de Estado' admite hoje a sociedade. Cabe tratar de como deve ser o Estado, isto é, refletir, no contexto de diminuição quantitativa do Estado, acerca de como o Estado se mantém e se fortalece. E isso se produz, em minha opinião, através da integração da sociedade com o Estado." FONT Y LLOVET, Tomás. Desarrollo reciente de los instrumentos de la administración consensual en España. In: MOREIRA NETO, Diogo de Figueiredo (coord.). Uma avaliação das tendências contemporâneas do Direito Administrativo, 2003, p. 364, tradução livre.

2 "Em uma época em que a capacidade regulatória de investimento do Estado se acha, muito particularmente no que tange aos Estados superendividados da periferia e da semiperiferia capitalistas, bastante reduzida, adotar modelos menos centralizadores e rígidos de planejamento não é apenas uma opção ideológica: é uma necessidade econômica e política". SOUZA, Marcelo Lopes. Mudar a cidade: uma introdução crítica ao planejamento e à gestão urbanos, 3. ed., 2003, p. 53.
} 
elaborados, mas raramente são aplicados". ${ }^{3}$ Assim, a operação urbana consorciada pode traduzir-se em alternativa regulatória e de urbanificação.

Mas parece que o principal fator de importância do tema da operação urbana consorciada, que justifica o seu exame, é a condição de caos, concentração e desigualdade urbanas no Brasil, derivados do crescimento demográfico vertiginoso e desordenado, característico da segunda metade do século XX.

Diante dessa situação, a operação urbana consorciada emerge mais uma vez como alternativa, especialmente (reitere-se) em virtude da diminuída capacidade atual de investimento de recursos públicos.

Frise-se que para o desenvolvimento do trabalho parte-se do pressuposto de que não é possível compreender o direito urbanístico e seus instrumentos sem o prévio conhecimento do processo de urbanização, do desenvolvimento dos métodos e tendências do urbanismo e, em tempo, das normas que precederam a ordem vigente (especialmente em relação à disciplina normativa da operação urbana consorciada). ${ }^{4}$

Assim, a metodologia envolveu a consulta e organização de dados e o estudo da literatura especializada relativamente à urbanização, ao urbanismo, a experiências concretas de utilização de operações urbanas, e à evolução do tratamento jurídico dispensado ao tema. Como se vê, propõe-se uma metodologia que não pode deixar de atentar para a interdisciplinaridade, na condição de caractere necessário do direito urbanístico. $^{5}$

Por tudo isso, o primeiro capítulo do trabalho trata da contextualização técnicojurídica das operações urbanas. Haverá a exposição de métodos e concepções do urbanismo, que demonstram a evolução dessa ciência. A partir disso será possível aferir o contexto das operações, situadas no que se chama de urbanismo operacional-concertado (mescla das concepções do urbanismo operacional e do urbanismo concertado).

Ao final desse capítulo mostra-se o aparecimento de novos métodos do urbanismo (participativo, de gestão e de comunicação), remissíveis às operações urbanas e que propõem, respectivamente, (i) a consideração, pelo urbanista, da dinâmica social, mediante

${ }^{3}$ MEDAUAR, Odete. Diretrizes Gerais. In: MEDAUAR, Odete, ALMEIDA, Fernando Dias Menezes de (coord.). Estatuto da Cidade: Lei 10.257, de 10.07.2001, comentários. 2. ed., 2004, p. 29.

4 “O direito urbanístico não é matéria simples, e sim complexa, mas há um método infalível para não o entender nunca: consiste em entrar diretamente no estudo da normativa vigente, prescindindo das suas transformações, da sua regulação por outras normas que lhe tenham precedido." PARADA, Ramón. Derecho urbanístico general, 2007, p. 21, tradução livre.

${ }^{5}$ MEDAUAR, Odete. Caracteres do Direito Urbanístico. Revista de Direitos Difusos. Direito Urbanístico e qualidade de vida nas cidades, v. 2, 2000, p. 133. 
a participação popular e o compartilhamento das decisões públicas, (ii) a observação e o aproveitamento, pelo Poder Público, do mercado imobiliário, e (iii) o desenvolvimento da aptidão da cidade para atrair novas empresas e investimentos. Também há menção ao advento de novas concepções de cidade: as cidades-globais e as cidades corporativas, que traduzem apreciações sistematizadas da cidade como centro decisório mundial e da fragilidade da ordenação das cidades em face das decisões das grandes empresas.

O segundo capítulo tratará das dimensões jurídicas e da conceituação da operação urbana consorciada. Adiante-se que o presente trabalho sugere um conceito próprio para o instrumento, em virtude da verificação da insuficiência do conceito fornecido pelo Estatuto da Cidade.

O terceiro capítulo propõe-se ao exame da disciplina e do desenvolvimento da operação urbana consorciada, a partir de um roteiro fundamentado nas disposições do Estatuto da Cidade. Em seguida, e no quarto capítulo, são apresentados outros institutos, inclusive do direito estrangeiro, que serviram de inspiração à configuração atual da operação urbana consorciada.

Por fim, o quinto capítulo destina-se a enfrentar a problemática sócio-jurídica atinente às operações urbanas consorciadas, a partir do exame de vícios e de perspectivas de adequação da operação às diretrizes da política urbana. 


\section{CONCLUSÕES}

O presente trabalho destinou-se a identificar a operação urbana consorciada como instrumento de intervenção urbanística e de regulação do mercado imobiliário, e a esmiuçar suas características. Além disso, procurou-se apresentar o gênero das operações urbanas, especialmente no tocante a instrumentos que serviram de inspiração à operação urbana consorciada, e buscou-se o oferecimento de subsídios para a compreensão de sua problemática sócio-jurídica.

Conforme exposto ao longo do trabalho, a operação urbana consorciada é uma espécie de operação urbana vinculada à concepção do urbanismo operacional-concertado. Em outras palavras, trata-se de um instrumento de efetiva intervenção urbanística, que não se restringe à proteção do exercício do direito de propriedade individual ou à composição urbana, e que congrega atuação pública e privada.

Nesse contexto, e com fundamento na análise das suas dimensões jurídicas, a operação urbana consorciada foi definida como "um empreendimento urbano, capitaneado pelo poder público municipal e desenvolvido em parceria com a sociedade civil, financiado no todo ou em parte pelas contrapartidas decorrentes da execução de um plano urbanístico flexível, e traduzido num procedimento urbanístico orientado cumulativamente à transformação urbanística estrutural, à valorização ambiental e à promoção de melhorias sociais numa determinada área do espaço habitável”.

A partir dessa definição e do exame do ordenamento jurídico, propôs-se que a competência para a instituição e a coordenação de operações urbanas consorciadas é municipal, mas sem prejuízo do cabimento da atuação concertada entre diversos entes da Federação, quando estiverem presentes interesses justapostos.

Indicou-se ainda que a instituição de uma operação urbana consorciada depende da edição de lei específica, que deverá ser resultado de um processo participativo de planejamento (e que, em última análise, apresentará o plano da operação).

Dessa lei e do plano, por imposição do Estatuto da Cidade (art. 33), deverão constar os seguintes elementos: definição e programa de ocupação da área a ser atingida, programa de atendimento à população diretamente afetada, finalidades da operação, estudo prévio de impacto de vizinhança e, quando for o caso, de impacto ambiental, benefícios, contrapartidas e forma de controle, compartilhado com a sociedade civil. 
Mas há outro elemento fundamental e indissociável da operação urbana consorciada, consistente na execução do regime urbanístico diferenciado concebido para a área focalizada. Isso se fará através de parceria público-privada, mediante a concessão de benefícios urbanísticos pelo poder público e o recebimento de contrapartidas correspondentes, orientadas ao financiamento da urbanificação.

Lembre-se, nesse ponto, a relevância da operação urbana consorciada como alternativa de intervenção urbanística no contexto de redução quantitativa das funções do Estado e da sua capacidade de investimentos, de gestão e de controle.

Afinal, a operação urbana consorciada demandará o aporte de recursos privados, na forma de contrapartidas aos benefícios urbanísticos concedidos. Além disso, e tal como já se adiantou, a gestão e o controle da operação deverão ser compartilhados com a sociedade civil (sendo recomendável a criação de um órgão gestor permanente e de um órgão colegiado paritário, que exercerá funções de controle, consulta, deliberação e resolução de conflitos).

Note-se ainda que a realização concreta de uma operação urbana consorciada está sujeita a vícios relacionados, em suma, (i) a desvios de finalidade, nas circunstâncias de o instrumento servir precipuamente a função arrecadatória ou aos interesses do mercado imobiliário (lembre-se a questão da captura regulatória), (ii) a inversão de prioridades, pelo deslocamento de investimentos em áreas mais necessitadas e, por conseguinte, a inflação de investimentos em áreas já privilegiadas, e (iii) a excessiva valorização imobiliária, que produzirá a expulsão de usos e a gentrificação, quando não houver a previsão de medidas compensatórias.

Muitos desses vícios acometeram experiências concretas de operações, inclusive estrangeiras, citadas no corpo do trabalho. No caso da operação urbana consorciada, o enfrentamento desses vícios constituirá um desafio que demandará medidas orientadas à retomada da coerência do instrumento em face das diretrizes da política urbana.

Nesse contexto, sobressai a importância da adequada definição da área da operação, especialmente quando se tem em vista que as contrapartidas oriundas da concessão de benefícios urbanísticos somente poderão financiar a urbanificação nos limites da operação.

Ademais, sugere-se que sejam realizadas pequenas intervenções, de modo a conter e a melhor controlar a valorização imobiliária. Também são propostas contrapartidas não pecuniárias, tais como a realização de obras de interesse social, sempre no sentido da adequação da operação às diretrizes da política urbana. E reconhece-se que outro 
determinante do desenvolvimento sadio de uma operação urbana consorciada reside na efetivação da gestão democrática e do controle pela sociedade civil, inclusive mediante utilização do método do urbanismo participativo.

Enfim, é necessário que o Poder Público tome em consideração a importância da adequada configuração da operação urbana consorciada em face dos dados concretos e de sua inserção no mercado imobiliário, para produzir intervenções de sucesso. 


\section{REFERÊNCIAS BIBLIOGRÁFICAS}

AGLIETTA, Michel. Régulation et crises du capitalisme - L'expéricente des EtatsUnis. Paris: Calmann-Lévy, 1982.

ALBUQUERQUE, Marcos Cintra Cavalcanti. Novas fontes de investimentos públicos. Disponível em http://www.portalbrasil.net/2004/colunas/economia/setembro.htm, acesso em 21.04.2010.

ALFONSIN, Betânia de Moraes. Operações urbanas consorciadas como instrumento de captação de mais-valias urbanas: um imperativo da nova ordem jurídico-urbanística brasileira. In: ALFONSIN, Betânia de Moraes, FERNANDES, Edésio. Direito urbanístico: estudos brasileiros e internacionais. Belo Horizonte: Del Rey, 2006.

BREWER-CARÍAS, Allan-Randolf. La urbanización en Venezuela y la ausencia de un derecho urbanístico. In: INSTITUTO DE DIREITO PÚBLICO. Archivo de Derecho Público y Ciencias de la Administración, coord. por Allan-Randolf Brewer-Carías, vol. V. Caracas: 1982.

ALMEIDA, Fernanda Dias Menezes de. Competências na Constituição Federal de 1988. 4. ed. São Paulo: Atlas, 2007.

ALMEIDA, Fernando Dias Menezes de. Dos instrumentos da política urbana. In: MEDAUAR, Odete, ALMEIDA, Fernando Dias Menezes de. Estatuto da Cidade: Lei 10.257, de 10.07.2001, comentários. 2. ed., rev., atual. e ampl. São Paulo: Revista dos Tribunais, 2004.

Mecanismos de consenso no Direito Administrativo. In: ARAGÃO, Alexandre Santos de, MARQUES NETO, Floriano de Azevedo. Direito administrativo e seus novos paradigmas. Belo Horizonte: Fórum, 2008.

ALVES, Alaôr Caffé. Planejamento metropolitano e autonomia municipal no direito brasileiro. São Paulo: Bushatsky: EMPLASA, 1981.

AMARAL FILHO, Marcos Jordão Teixeira do. Da gestão democrática da cidade. In: MEDAUAR, Odete, ALMEIDA, Fernando Dias Menezes de (coord.). Estatuto da Cidade: Lei 10.257, de 10.07.2001, comentários. 2. ed., rev., atual. e ampl. São Paulo: Revista dos Tribunais, 2004.

AUBY, Jean-Bernard, PÉRINET-MARQUET, Hugues, NOGUELLOU, Rozen. Droit de l'urbanisme et de la construction. 8. ed. Paris: Éditions Montchrestien, 2008.

BASTOS, Celso Ribeiro, MARTINS, Ives Gandra da Silva. Comentários à Constituição do Brasil, v. 4, t. 1. São Paulo: Saraiva, 1988.

BATISTELA, Marcos. Operações urbanas consorciadas. In: DALLARI, Adilson Abreu, DI SARNO, Daniela Campos Libório. Direito urbanístico e ambiental. Belo Horizonte: Fórum, 2007.

BERMAN, Marshall. Tudo que é sólido desmancha no ar - A aventura da 
modernidade. Trad. Carlos Felipe Moisés e Ana Maria L. Ioriatti. São Paulo: Companhia das Letras, 2007.

BLAUT, James M. The Colonizer's Model of the World: geographical diffusionism and eurocentric history. New York - London: The Guilford Press, 1992.

BORGES, Alice Gonzales. Operações urbanas consorciadas: os consórcios intermunicipais como instrumentos de realização do estatuto da cidade. In: WAGNER JÚNIOR, Luiz Guilherme da Costa (coord.). Direito público: estudos em homenagem ao professor Adilson Abreu Dallari. Belo Horizonte: Del Rey, 2004.

CABRAL, Lucíola Maria de Aquino. Operação urbana consorciada: possibilidades e limitações (possibilidade de implantação sem prévio parcelamento do solo; óbices à incorporação de recurso hídrico). Revista Magister de Direito Ambiental e Urbanístico, n. 19, p. 9-39, ago./set. 2008. Porto Alegre: Magister, 2008.

CARDOSO, Adauto Lucio. A cidade e seu estatuto: uma avaliação urbanística do Estatuto da Cidade. In: RIBEIRO, Luiz Cesar de Queiroz, CARDOSO, Adauto Lucio (org.). Reforma urbana e gestão democrática: promessas e desafios do Estatuto da Cidade. Rio de Janeiro: Revan: FASE, 2003.

CARMONA, Paulo Afonso Cavichioli. O consórcio imobiliário como instrumento de intervenção urbanística. Belo Horizonte: Fórum, 2007.

CARVAlHO FILHO, José dos Santos. Comentários ao Estatuto da Cidade. 3. ed., rev., ampl. e atual. Rio de Janeiro: Lumen Juris, 2009.

CAVALLAZZI, Rosângela Lunardelli. O estatuto epistemológico do direito urbanístico brasileiro: possibilidades e obstáculos na tutela do direito à cidade. Revista Magister de Direito Ambiental e Urbanístico, n. 13, p. 24-40, ago./set. 2007. Porto Alegre: Magister, 2007.

CODE DE L'URBANISME. Disponível em: http://www.legifrance.gouv.fr/affichCode.do ?cidTexte=LEGITEXT000006074075.

COMPANS, Rose. Empreendedorismo urbano: entre o discurso e a prática. São Paulo: Editora UNESP, 2005.

CORREIA, Fernando Alves. Manual de direito do urbanismo, vol. I. Coimbra: Livraria Almedina, 2001.

Almedina, 1989.

O plano urbanístico e o princípio da igualdade. Coimbra: Livraria COSTA, Thales Morais da (coord.). Introdução ao direito francês. Curitiba: Juruá, 2009.

DALlARI, Adilson Abreu. Concessões urbanísticas. Revista Trimestral de Direito Público n. 37/2002, p. 13-21. São Paulo: Malheiros, 2002.

Instrumentos da política urbana. In: DALLARI, Adilson Abreu, FERRAZ,

Sérgio. Estatuto da Cidade (Comentários à Lei Federal 10.257/2001). 3. ed. São Paulo: Malheiros Editores, 2010. 
DANIEL, Celso. A gestão local no limiar do novo século: desafios dos governos democráticos e populares no Brasil. In: FERNANDES, Edésio (org.). Direito urbanístico e política urbana no Brasil. Belo Horizonte: Del Rey, 2000.

DEÁK, Csaba. Rent theory and the price of urban land - Spatial organization in a capitalist economy. PhD Thesis. King's College, University of Cambridge. Cambridge: mimeo, 1985.

DEBORD, Guy. A sociedade do espetáculo. São Paulo: Contraponto, 2008.

DEMEURE, Sylvain, MARTIN, Jean-Yves, RICARD, Michel. La ZAC. 2. ed. Paris: Le Moniteur, 2008.

DI GIUSEPPE, Diana. Operações urbanas consorciadas. In: FUNDAÇÃO PREFEITO FARIA LIMA - CEPAM. Estatuto da Cidade, coord. por Mariana Moreira. São Paulo: Fundação Prefeito Faria Lima - CEPAM, 2001.

DI SARNO, Daniela Campos Libório. Elementos de direito urbanístico. Barueri: Manole, 2004.

DICIONÁRIOS “ACADÉMICOS”. Francês-Português e Português-Francês. Porto: Porto Editora, 1982.

DICKENS, Charles. Oliver Twist. 2. ed. London: Penguin Popular, 2007.

DOCKLANDS CONSULTATIVE COMMITTEE. The Docklands experiment: a critical review of eight years of the London Docklands Development Corporation. London: DCC, 1990.

DOMINGUES, Rafael Augusto Silva. Competência constitucional em matéria de urbanismo. In: DALLARI, Adilson Abreu, DI SARNO, Daniela Campos Libório. Direito urbanístico e ambiental. Belo Horizonte: Fórum, 2007.

ENTERRÍA, Eduardo Garcia, ALFONSO, Luciano Parejo. Lecciones de derecho urbanístico, I. Madrid: Editorial Civitas, 1979.

FAGUNDES, Miguel Seabra. Aspectos jurídicos do solo criado. Revista de Direito Administrativo, v. 129, p. 1-10, jun./set. 1977. Rio de Janeiro: FGV, 1977.

FERNANDEZ, Antonio Carceller. Instituciones de Derecho Urbanístico. Madrid: Editorial Monecorvo, 1977.

1981.

Instituciones de derecho urbanístico. 2. ed. Madrid: Editorial Montecorvo,

FERREIRA, João Sette Whitaker. São Paulo: o mito da cidade-global. Tese de doutoramento. Faculdade de Arquitetura e Urbanismo da Universidade de São Paulo. São Paulo: mimeo, 2003.

FERREIRA, Sérgio de Andréa. Política Urbana - Operação Interligada - Ato administrativo negocial - Competência do Prefeito (parecer). Boletim de Direito Municipal, n. 11, p. 847-865, nov./2002. São Paulo: NDJ, 2002. 
FIX, Mariana. Parceiros da exclusão- Duas histórias da construção de uma "nova cidade” em São Paulo: Faria Lima e Água Espraiada. São Paulo: Boitempo, 2001.

FONT Y LLOVET, Tomás. Desarrollo reciente de los instrumentos de la administración consensual en España. In: MOREIRA NETO, Diogo de Figueiredo (coord.). Uma avaliação das tendências contemporâneas do Direito Administrativo. Rio de Janeiro São Paulo: Renovar, 2003.

GASPARINI, Diógenes. O Estatuto da Cidade. São Paulo: NDJ, 2002.

Zoneamento urbano. Revista de Direito Público, n. 93, p. 257-260, jan./mar. 1990. São Paulo: RT, 1990.

GÉRARD, Patrick. Pratique du droit de l'urbanisme. Paris: Eyrolles, 1993.

GILLI, Jean-Paul, LANVERSIN, Jacques de. Lexique Droit de l'urbanisme. Paris: Presses Universitaires de France, 1978.

GRANELLE, Jean Jacques. As experiências da política fundiária na França. As experiências da política fundiária na França. In: PESSOA, Álvaro (coord.). Direito do urbanismo: uma visão sócio-jurídica. Rio de Janeiro: Livros Técnicos e Científicos: Instituto Brasileiro de Administração Municipal, 1981.

GRAU, Eros Roberto. Aspectos jurídicos da noção de solo criado. In: FUNDAÇÃO PREFEIRO FARIA LIMA - CEPAM. Solo Criado/Carta do Embu: anais do Seminário “O Solo Criado”. S. 1.: Fundação Prefeito Faria Lima - CEPAM: 1977.

GUERRA, Maria Magnólia Lima. Aspectos jurídicos do uso do solo urbano. Fortaleza: s.e., 1981.

HUGO, Victor. Os miseráveis. 3. ed. Trad. Frederico Ozanam Pessoa de Barros. São Paulo: Cosac Naify, 2009.

HUYCK, Alfred P. Van, HORNUNC, Jack. The Citizen's Guide to Urban Renewal. West Trenton, New Jersey: Chandler-Davis Publishing Company, 1962.

INSTITUTO BRASILEIRO DE GEOGRAFIA E ESTATÍSTICA. Disponível em: http://ibge.gov.br/home/presidencia/noticias/noticia_visualiza.php?id_noticia=1246\&id_pa gina $=1$, acesso em 22.09.2009.

INSTITUTO PÓLIS. Estatuto da Cidade - Guia para implementação pelos municípios e cidadãos, coord. por Raquel Rolnik. Brasília: Câmara dos Deputados, 2001.

JACOBS, Jane. Morte e vida de grandes cidades Trad. Carlos S. Mendes Rosa. São Paulo: Martins Fontes, 2007.

JACQUOT, Henri, PRIET, François. Droit de l'urbanisme. 4. ed., Paris: Dalloz, 2001.

JORGENSEN JÚNIOR, Pedro. Operações urbanas: uma ponte necessária entre a regulação urbanística e o investimento direto. Cadernos de urbanismo, n. 3, nov. 2000. Rio de Janeiro: Prefeitura do Rio de Janeiro, 2000. 
JUSTEN FILHO, Marçal. Curso de Direito Administrativo. 5. ed., rev. e atual. São Paulo: Saraiva, 2009.

LACAZE, Jean-Paul. Os métodos do urbanismo. Trad. Marina Appenzeller. Campinas: Papirus, 1993.

LANDER, Edgardo (org.). A colonialidade do saber: eurocentrismo e ciências sociais. Perspectivas latino-americanas. Buenos Aires: CLACSO, 2005.

LE CORBUSIER. Planejamento urbano. Trad. Lúcio Gomes Machado. 3. ed. São Paulo: Perspectiva, s.a.

LE ROBERT MICRO, Dictionnaire de la langue française. Paris: Dictionnaires Le Robert, 1998.

LEAL, Rogério Gesta. Direito urbanístico: condições e possibilidades da constituição do espaço urbano. Rio de Janeiro: Renovar, 2003.

LEBRETON, Jean-Pierre. Droit de l'urbanisme. Paris: Presses Universitaires de France, 1993.

LOCAL GOVERNMENT, PLANNING AND LAND ACT, 1980. Disponível em http://www.opsi.gov.uk/RevisedStatutes/Acts/ukpga/1980/cukpga_19800065_en_1, acesso em 23.04.2010.

LOJKINE, Jean. O Estado Capitalista e a questão urbana. Trad. Estela dos Santos Abreu. São Paulo: Martins Fontes, 1981.

LOMAR, Paulo José Villela. Operação urbana consorciada. In: DALLARI, Adilson Abreu, FERRAZ, Sérgio (coord.). Estatuto da Cidade (Comentários à Lei Federal 10.257/2001). 3. ed. São Paulo: Malheiros Editores, 2010.

MARICATO, Ermínia, FERREIRA, João Sette Whitaker. Operação urbana consorciada: diversificação urbanística participativa ou aprofundamento da desigualdade? In: OSÓRIO, Letícia Marques. Estatuto da Cidade e reforma urbana: novas perspectivas para as cidades brasileiras. Porto Alegre: Sergio Antonio Fabris Editor, 2002.

MARQUES NETO, Floriano de Azevedo. Bens públicos: função social e exploração econômica: o regime jurídico das utilidades públicas. Belo Horizonte: Fórum, 2009.

Outorga onerosa do direito de construir [solo criado]. In: DALLARI, Adilson Abreu, FERRAZ, Sérgio (coord.). Estatuto da Cidade (Comentários à Lei Federal 10.257/2001). 3. ed. São Paulo: Malheiros Editores, 2010.

MARTINS, Maria Lúcia Refinetti. Lei Federal do Parcelamento do Solo - tensão e diálogo entre o Direito à Cidade e o Direito Urbanístico e Ambiental. Fórum de Direito Urbano e Ambiental - FDUA, n. 31, p. 83-91, jan./fev. 2007. Belo Horizonte: Fórum, 2002.

MEDAUAR, Odete, OLIVEIRA, Gustavo Justino de. Consórcios públicos: comentários à Lei 11.107/2005. São Paulo: Revista dos Tribunais, 2006. 
MEDAUAR, Odete. Caracteres do Direito Urbanístico. Revista de Direitos Difusos. Direito Urbanístico e qualidade de vida nas cidades, v. 2. São Paulo: Adocas, 2000.

Destinação dos bens expropriados. São Paulo: Max Limonad, 1986.

Diretrizes Gerais. In: MEDAUAR, Odete, ALMEIDA, Fernando Dias Menezes de (coord.). Estatuto da Cidade: Lei 10.257, de 10.07.2001, comentários. 2. ed., rev., atual. e ampl. São Paulo: Revista dos Tribunais, 2004.

MEIRELLES, Hely Lopes. Direito municipal brasileiro. 13. ed. São Paulo: Malheiros, 2003.

MELLO, Celso Antônio Bandeira de. Natureza Jurídica do Zoneamento; Efeitos. Revista de Direito Público, n. 61, p. 34-47, jan./mar. 1982. São Paulo: RT, 1982.

MELLO, Oswaldo Aranha Bandeira de. Princípios gerais de direito administrativo, v. 1, 2. ed.. Belo Horizonte - Rio de Janeiro: Forense, 1979.

MIRRA, Álvaro Luiz Valery. Estudo de impacto de vizinhança no direito brasileiro. In: MARQUES, Claudia Lima, MEDAUAR, Odete, SILVA, Solange Teles. O novo direito administrativo, ambiental e urbanístico - Estudos em homenagem à Jacqueline Morand-Deviller. São Paulo: RT, 2010.

MONTANDON, Daniel Todtmann, SOUZA, Felipe Francisco de. Land readjustment e operações urbanas consorciadas. São Paulo: Romano Guerra Editora, 2007.

MORAND-DEVILLER, Jacqueline. Droit de l'urbanisme. 3. ed. Paris: Editions Dalloz, 1996.

MOREIRA NETO, Diogo de Figueiredo. Direito da participação política - Legislativa Administrativa - Judicial (Fundamentos e técnicas constitucionais da democracia). Rio de Janeiro: Renovar, 1992.

Forense, 1975.

Introdução ao direito ecológico e ao direito urbanístico. São Paulo: Mutações do Direito Administrativo. Rio de Janeiro: Renovar, 2000.

NOBRE, Eduardo Alberto Cuce. O projeto das London Docklands. S.1., mimeo, s.a.

OLIVEIRA, Fernanda Paula Marques de. As medidas preventivas dos planos municipais de ordenamento do território - alguns aspectos do seu regime jurídico. Coimbra: Coimbra Editora, 1998.

OLIVEIRA, Gustavo Justino de. Contrato de gestão. São Paulo: Revista dos Tribunais, 2008.

OLIVEIRA, Régis Fernandes de. Comentários ao Estatuto da Cidade. 2. ed. rev., atual. e ampl. São Paulo: Revista dos Tribunais, 2005. 
PALMA, Juliana Bonacorsi de. Atuação administrativa consensual: estudos dos acordos substitutivos no processo administrativo sancionador. Dissertação de mestrado. Faculdade de Direito da Universidade de São Paulo. São Paulo: mimeo, 2009.

PARADA, Ramón. Derecho urbanístico general. Madrid: Marcial Pons, 2007.

PINTO, Victor Carvalho. Direito urbanístico: plano diretor e direito de propriedade, 2. ed., rev. e atual. São Paulo: RT, 2010.

PRADO JÚNIOR, Caio. Evolução política do Brasil. 10. ed. São Paulo: Brasiliense, 1977.

PREFEITURA DE PARIS (MAIRIE DE PARIS). Disponível em: http://www.paris.fr/portail/Urbanisme/Portal.lut?page_id=101, acesso em 26.07.2009.

PRESTES, Vanêsca Buzelato. Plano diretor e estudo de impacto de vizinhança (EIV). Revista de Direito Ambiental, n. 37, p. 80-95, jan./mar. 2005. São Paulo: RT, 2005.

REQUIÃO, Rubens. Curso de Direito Comercial, v. 1. 25. ed. São Paulo: Saraiva, 2003.

SALOMÃO FILHO, Calixto. Regulação da atividade econômica (princípios e fundamentos jurídicos). 2. ed. São Paulo: Malheiros, 2008.

SANT'ANNA, Mariana Senna. Estudo de impacto de vizinhança: instrumento de garantia da qualidade de vida dos cidadãos urbanos. Belo Horizonte: Fórum, 2007.

SANTOS, Márcia Walquíria Batista dos. Dos instrumentos da política urbana - arts. 28 a 35. In: MEDAUAR, Odete, ALMEIDA, Fernando Dias Menezes de (coord.). Estatuto da Cidade: Lei 10.257, de 10.07.2001, comentários. 2. ed., rev., atual. e ampl. São Paulo: Revista dos Tribunais, 2004.

SANTOS, Milton. A urbanização brasileira. São Paulo: Editora HUCITEC, 1993.

SASSEN, Saskia. The Global City - New York, London, Tokyo. New Jersey: Princeton University Press, 1991.

SCHIFFER, Sueli. Novos instrumentos de gestão urbana: entre as transformações socioeconômicas e a participação de organizações sociais. Sevilha: mimeo, 2006.

SCHUMPETER, Joseph Alois. A teoria do desenvolvimento econômico: uma investigação sobre lucros, capital, crédito, juro e o ciclo econômico. Trad. Maria Sílvia Possas. São Paulo: Abril Cultural, 1982.

SILVA, José Afonso da. Comentário contextual à Constituição. São Paulo: Malheiros, 2005.

Direito urbanístico brasileiro. 2. ed. São Paulo: Malheiros, 1995.

2008.

Direito urbanístico brasileiro. 5. ed. rev. e atual. São Paulo: Malheiros, 
SOMENSI, Simone, PRESTES, Vanêsca Buzelatto. Regularização fundiária como política pública permanente: teoria e prática. Revista Interesse Público, n. 59, p. 229-248, jan./fev. 2010. Belo Horizonte: Fórum, 2010.

SORENSEN, André. Land readjustment and metropolitan growth: an examination of suburban land development and urban sprawl in the Tokyo metropolitan area. In: Progress in Planning n. 53, 2000, disponível em: http://hdl.handle.net/1807/2757, acesso em: 23.04.2010.

SOUSA, António Francisco de. "Conceitos indeterminados" no direito administrativo. Coimbra: Almedina, 1994.

SOUZA, Marcelo Lopes. Mudar a cidade: uma introdução crítica ao planejamento e à gestão urbanos. 3. ed. Rio de Janeiro: Bertrand Brasil, 2003.

SUNDFELD, Carlos Ari. Direito de construir e novos institutos urbanísticos. Revista da Pós-Graduação em Direito PUC-SP, n. 2, p. 5-52, 1995. São Paulo: Max Limonad, 1995.

. Guia jurídico das parcerias público-privadas. In: SUNDFELD, Carlos Ari (coord.). Parcerias Público-Privadas, 2005.

. O Estatuto da Cidade e suas diretrizes gerais. In: DALLARI, Adilson Abreu, FERRAZ, Sérgio (coord.). Estatuto da Cidade (Comentários à Lei Federal 10.257/2001). 2. ed. São Paulo: Malheiros Editores, 2006.

TOBA, Marcos Maurício. Do Plano Diretor. In: MEDAUAR, Odete, ALMEIDA, Fernando Dias Menezes de (coord.). Estatuto da Cidade: Lei 10.257, de 10.07.2001, comentários. 2. ed., rev., atual. e ampl. São Paulo: Revista dos Tribunais, 2004.

TRIBUNAL DE JUSTIÇA DO ESTADO DE SÃO PAULO. Órgão Especial. Agravo regimental em ação direta de inconstitucionalidade n. 45.352.0/7-01. Rel. Des. José Osório. Julg. $1^{\circ} .04 .2008$.

VICHI, Bruno de Souza. O Direito Urbanístico e as regras de competência na Constituição brasileira e no Estatuto da Cidade. In: DALLARI, Adilson Abreu, DI SARNO, Daniela Campos Libório. Direito urbanístico e ambiental. Belo Horizonte: Fórum, 2007.

VILARINO, Maria do Carmo. Operação urbana: a inadequação do instrumento para promoção de áreas em declínio. Tese de doutoramento. Faculdade de Arquitetura e Urbanismo da Universidade de São Paulo. São Paulo: mimeo, 2006. 